\section{SOI: 1.1/TAS DOI: $10.15863 /$ TAS International Scientific Journal Theoretical \& Applied Science}

p-ISSN: 2308-4944 (print) e-ISSN: 2409-0085 (online)

Year: $2016 \quad$ Issue: 12 Volume: 44

Published: $30.12 .2016 \quad$ http://T-Science.org

SECTION 8. Architecture and construction.
Oksana Oleksandrivna Dovzhenko

Phd. tehn, Associate Professor Poltava National Technical Yuriy Kondratyuk University o_o_dovzhenko@mail.ru

Volodymyr Volodymyrovuch Pohribnyi

Phd. tehn, Senior Researcher

Poltava National Technical Yuriy Kondratyuk University v_v_pohribnyy@mail.ru

Iryna Serhiivna Usenko

Phd. tehn, Associate Professor

Poltava National Technical Yuriy Kondratyuk University

Olena Oleksandrivna Mal'ovana Post-graduate

Poltava National Technical Yuriy Kondratyuk University alenka_malecha@mail.ru

Mkrtich Karapetovuch Akopyan Student Poltava National Technical Yuriy Kondratyuk University

\title{
CONCRETE ELEMENTS STRENGTH UNDER THE SHEAR ACTION ACCORDING TO THE VARIATION METHOD IN THE THEORY OF PLASTICITY AND TESTS
}

\begin{abstract}
There are great amount of concrete and reinforced concrete structures under the action of shear forces. They are important and widely used elements of buildings and constructions, and differ from each other by the construction determination, dimensions, forms and the character of stress-strain state in the shear plane. The strength design method is expounded for concrete and reinforced concrete elements by means of variation method in the concrete plasticity theory that was developed in Poltava National Technical University. There is also experimental investigation of the following elements: Gvozdev and Mersh specimens, wall-beams and truncated concrete wedges that simulate work of concrete compressed zone above dangerous inclined crack as the most wellknown from offered for the strain condition and failure load determination for considered types of elements. In addition wedges and Gvozdev specimens from higher strength concrete have been tested for applicability determination of given method to these elements. The results of the experimental research have confirmed the applicability of plasticity zones assumed in the theoretical solutions. The theoretical strength is well coordinated with the experimental one.

Key words: strength, shear action, variation method, truncated wedge, wall-beam, Gvozdev specimen.

Language: English

Citation: Dovzhenko OO, Pohribnyi VV, Usenko IS, Mal'ovana OO, Akopyan MK (2016) CONCRETE ELEMENTS STRENGTH UNDER THE SHEAR ACTION ACCORDING TO THE VARIATION METHOD IN THE THEORY OF PLASTICITY AND TESTS. ISJ Theoretical \& Applied Science, 12 (44): 12-18.

Soi: http://s-o-i.org/1.1/TAS-12-44-3 Doi: crossef http://dx.doi.org/10.15863/TAS.2016.12.44.3

\section{Introduction}

Concrete and reinforced concrete elements under the action of shear forces are important and widely used in the practice of construction. The mentioned elements include the beams and slabs, short elements, monolithic massive constructions. They all differ from each other in the construction determination, dimensions, forms and the character of stress-strain state in the shear plane.

The formulas available for prediction of the ultimate load carrying capacity vary widely and are

influenced by empirical factors. Most formulas are related to the shear friction hypothesis. Chakrabarti S. et al. [1] concluded that a theory based on the Mohr-Coulomb failure criterion should be used in preference to the shear friction theory. Jensen B. [7] established a formula for the load carrying capacity of vertical keyed shear joint based on the theory of plasticity. Christoffersen J. [2] expanded the application of plastic theory to include both upper and lower bound solutions in the description of the capacity of a keyed joint.
\end{abstract}




\begin{tabular}{|c|c|c|c|c|c|c|}
\hline Impact Factor: & $\begin{array}{l}\text { ISRA (India) } \\
\text { ISI (Dubai, UAF } \\
\text { GIF (Australia) } \\
\text { JIF }\end{array}$ & $\begin{array}{l}=1.344 \\
=0.829 \\
=0.564 \\
=1.500\end{array}$ & $\begin{array}{l}\text { SIS (USA) } \\
\text { PИНЦ (Russia) } \\
\text { ESJI (KZ) } \\
\text { SJIF (Morocco) }\end{array}$ & $\begin{array}{l}=0.912 \\
=0.234 \\
=1.042 \\
=2.031\end{array}$ & $\begin{array}{l}\text { ICV (Poland) } \\
\text { PIF (India) } \\
\text { IBI (India) }\end{array}$ & $\begin{array}{l}=6.630 \\
=1.940 \\
=4.260\end{array}$ \\
\hline
\end{tabular}

In [17] the load carrying capacity is calculated by use of the theory of plasticity assuming concrete and reinforcement steel to be regid-perfect plastic materials obeying the associated flow rule. The concrete is considered as a modified Coulomb material with zero tensile strength. Nielsen $\mathrm{M}$. and Hoang L. [13] proposed a formula for the determination of the energy dissipated per unit area of a failure surface for plain strain problem.

The variation method in the concrete plasticity theory is developed in PoltNTU for the strength design of the concrete and reinforced concrete elements [12]. It can be referred to the engineer design methods that bring to really easy relations, don't need an involvement of the complex computer programs and found wide distribution in the design practice.

Fundamental provisions of the strength design method

The method is based on the following preconditions:

1. The Balandin-Geniev strength condition is used [5]

$$
F\left(\sigma_{i j}\right)=T^{2}+m \sigma-T_{s h}^{2}=0,
$$

where $m=f_{c d}-f_{c t d}, \quad T_{s h}^{2}=f_{c d} f_{c t d} / 3 ; \quad T-$ intension of the tangent stresses; $\sigma$-average stress;

2. The associated law of yielding links together the irreversible deformation velocities $\xi_{i j}$ with stresses $\sigma_{i j}$;

$$
\xi_{i j}=\lambda \partial F / \partial \sigma_{i j}
$$

The velocity of the volumetric deformation $\xi_{i j}$ isn't equal to zero as a result of concrete dilatation, which is taken into account by a model;
3. Concrete in ultimate state is considered as ideally plastic material. As a result a specific capacity of the concrete deformation $W_{c}$ has been found as a function of the shear deformation velocities;

4. The model of rigid-plastic solid and solution in dissoluble functions of velocities were used;

5. The parameters of stress-strain state of reinforcement have been taken according to the surrounding concrete state.

The function of method in dissoluble functions of velocities for plane stress state is following:

$$
\begin{aligned}
& I_{l}=\int_{S_{l}} m\left[2 B\left(1+0,25\left(\Delta V_{t} / \Delta V_{n}\right)^{2}\right)^{0,5}-1\right] \times \\
& \times \Delta V_{n} d S_{l}-\int f_{i} V_{i} d S_{l},
\end{aligned}
$$

where $B^{2}=\left(1+\chi /(1-\chi)^{2}\right) / 3 ; \quad \chi=f_{c t d} / f_{c d}$; $\Delta V_{t}$ i $\Delta V_{n}$ - rupture of tangential and normal to $S_{l}$ components of velocity; $S_{l}$ - failure surface;

- external forces acing upon a solid; velocities of solid parts in direction of action of corresponding forces.

Gvozdev and Mersh specimens as the most well-known from the offered specimens for the determination of concrete strength under action of "pure shear" and truncated concrete wedges that model compressed concrete zone of bending elements above a dangerous inclined crack (DIC) have been considered.

Kinematially possible failure schemes of separate concrete elements and relationships for strength determination are submitted in table 1.

\section{Strength of concrete elements under shear action.}

Table 1

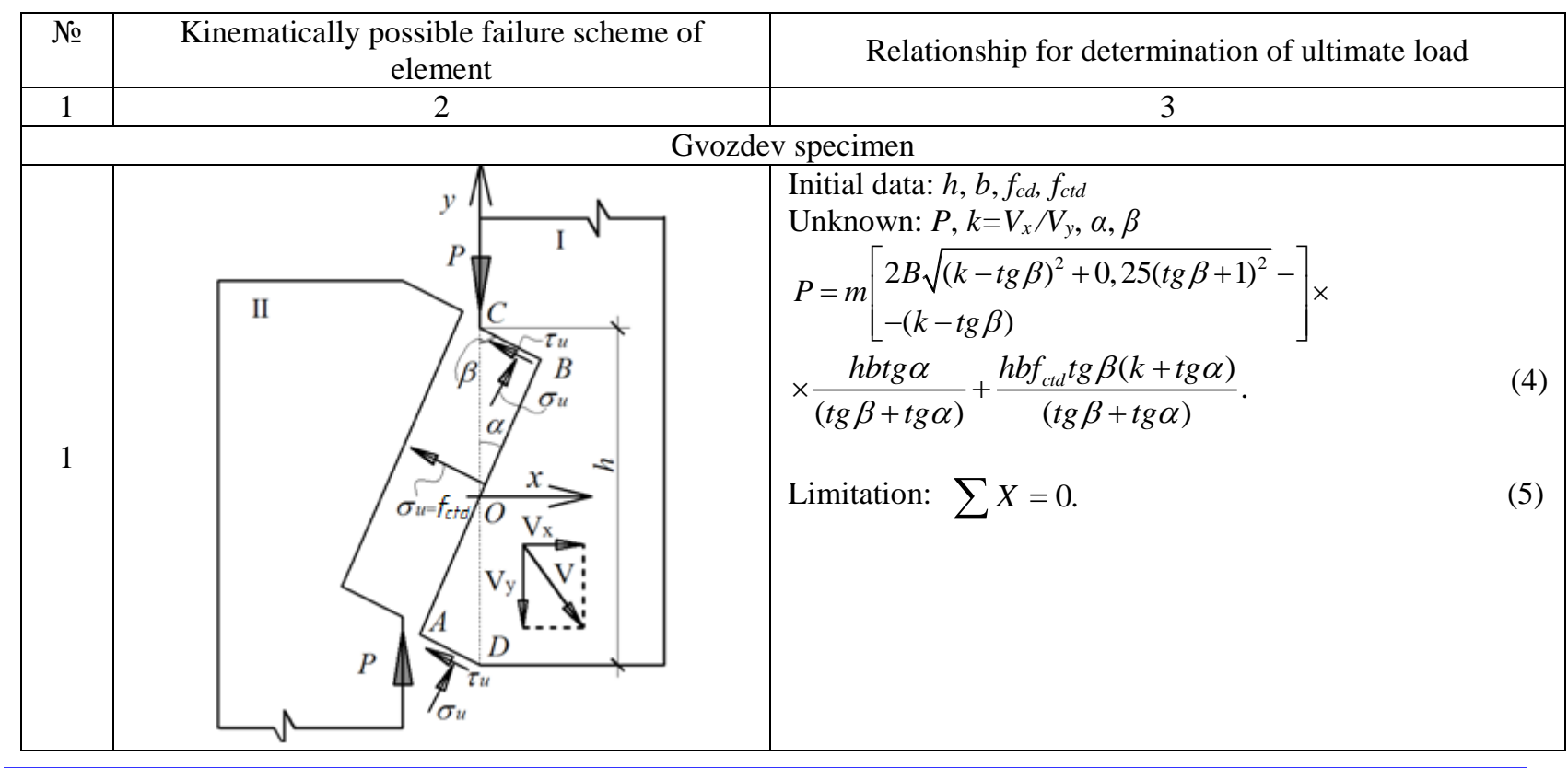

ISPC Generalization of scientific results, 


\begin{tabular}{l|lrl|l|ll} 
& ISRA (India) & $=\mathbf{1 . 3 4 4}$ & SIS (USA) & $=\mathbf{0 . 9 1 2}$ & ICV (Poland) & $=\mathbf{6 . 6 3 0}$ \\
Impact Factor: & ISI (Dubai, UAE) $=\mathbf{0 . 8 2 9}$ & PUHL (Russia) $=\mathbf{0 . 2 3 4}$ & PIF (India) & $=\mathbf{1 . 9 4 0}$ \\
& GIF (Australia) & $\mathbf{0 . 5 6 4}$ & ESJI (KZ) & $=\mathbf{1 . 0 4 2}$ & IBI (India) & $\mathbf{= 4 . 2 6 0}$ \\
& JIF & $\mathbf{1 . 5 0 0}$ & SJIF (Morocco) & $=\mathbf{2 . 0 3 1}$ & & \\
\hline
\end{tabular}

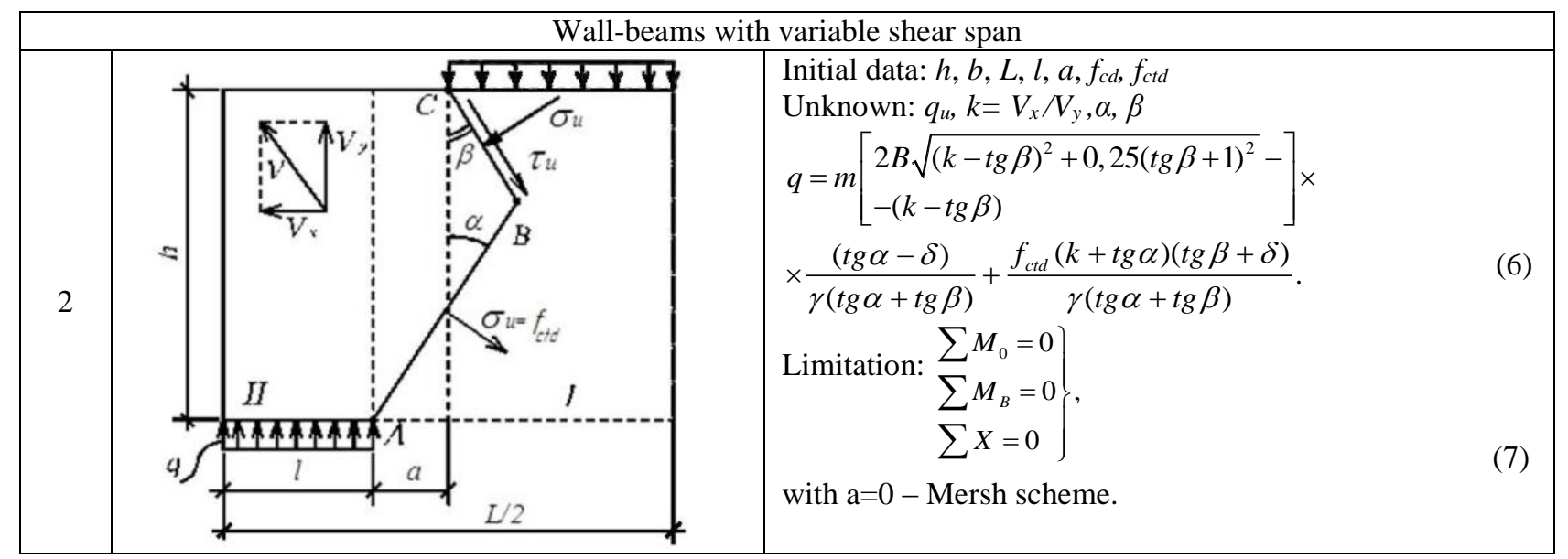

\begin{tabular}{|l|l|l|}
\hline 1 & \multicolumn{1}{|c|}{3} & \multicolumn{1}{|c|}{3} \\
\hline First case of truncated concrete wedge failure (with outlet of failure area on the facet that is adjacent to slant angle) \\
\hline
\end{tabular}

ISPC Generalization of scientific results, 


\section{Experimental researches}

The experimental program included the study of the strain condition and determination of failure load for considered types of elements.

Gvozdev samples. For taking up the tension stresses that appear in horizontal plane during loading, upper and lower parts of sample by external sides either were reinforced or pressed out with the help of external stirrups (fig. 1, a). 10 [16] and 7 [8] samples were made from heavy concrete of different classes.

The failure of samples took place by the surface which crossed the shear plane and almost coincided with it (fig. 2, a). Tensoresistores rates indicate the existence of compressed and tensile sections of failure surface. In the middle part of working section tension has been fixed, whereas compression has been found near inlet corners. a

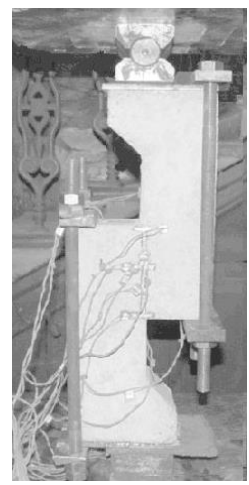

b

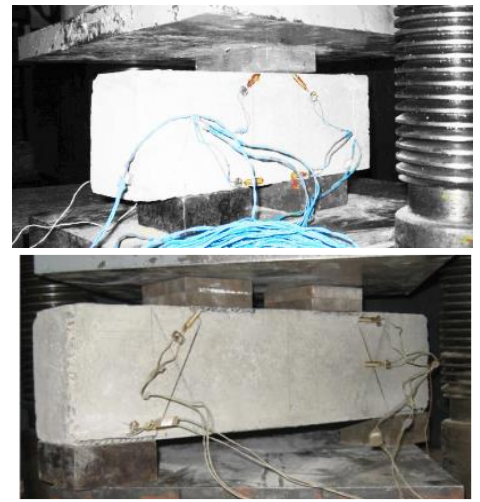

。

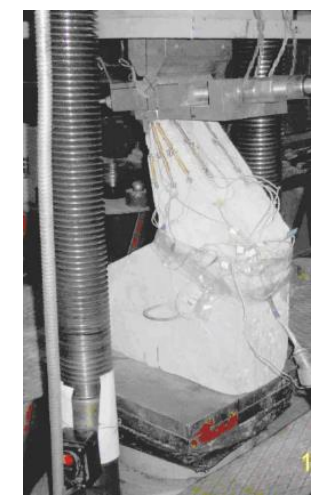

Figure 1 - Specimen in press during testing: a - Gvozdev sample; $b$ - Mersh sample; $c$ - beam-wall with variable shear span; $d$ - truncated concrete wedge.

There were also carried out additional researches concerning failure of Gvozdev samples of higher strength concrete. Scheme of their failure is similar to described before, what indicates the existence of the plasticity zones in Gvozdev samples of higher strength concrete. Development of plastic deformations has been observed in compressed zones of samples, although failure character was brittle.

Beam-walls with constant (Mersh samples) and variable shear span. During experimental researches of ten beam-walls from heavy concrete with height $h=150 \mathrm{~mm}$ that work after Mersh scheme (fig. 1, b) dimensions of lower plates varied $(l=80,100,150 \mathrm{~mm})$ that led to variation in experiment of parameter $\eta=l / h$.

For considered samples was typical that by load level of $0,5-0,7$ from failure in their lower part normal crack appeared, which retained its opening width as constant in the further loading.

During testing of 7 beam-walls from heavy concrete with variable shear span $a=0 \div 100 \mathrm{~mm}$ with gradation every $50 \mathrm{~mm}$ parameter $\eta=l / h$ was constant and equal to 0,65 (fig. 1, c).

Two failure cases were fixed - by the vertical (Mersh scheme) and inclined (with variable shear span) sections via displacement of central part of element vertically down relative to side (fig. 2, b, c).

It has been established that by increasing of shear span $a$ angle of slope of compressed zone to vertical and strength of samples decreased, and angle of slope of tensile zone to vertical increased.

Truncated concrete wedges. At the first stage $18(11+7)$ truncated wedges of claydite-concrete of two different classes by strength have been made [16]. During series wedge angle $\alpha\left(15^{\circ}, 30^{\circ}, 45^{\circ}\right)$ and load angle $\beta$ with constant $\alpha$ were varied from $0^{\circ}$ to $\alpha$ $+(0 \pm 10)^{\circ}$. At the second stage 17 claydite-concrete wedges have been tested [8], for those the force $P_{w}$ was directed as to the slant angle, as from it.

Low parts of specimens were reinforced for failure prevention. Load was transferred on truncated facet of element under different angles using special patented device (fig. 1, d). 


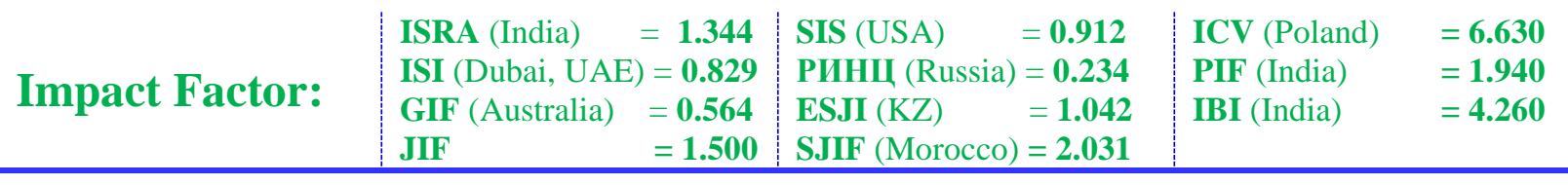

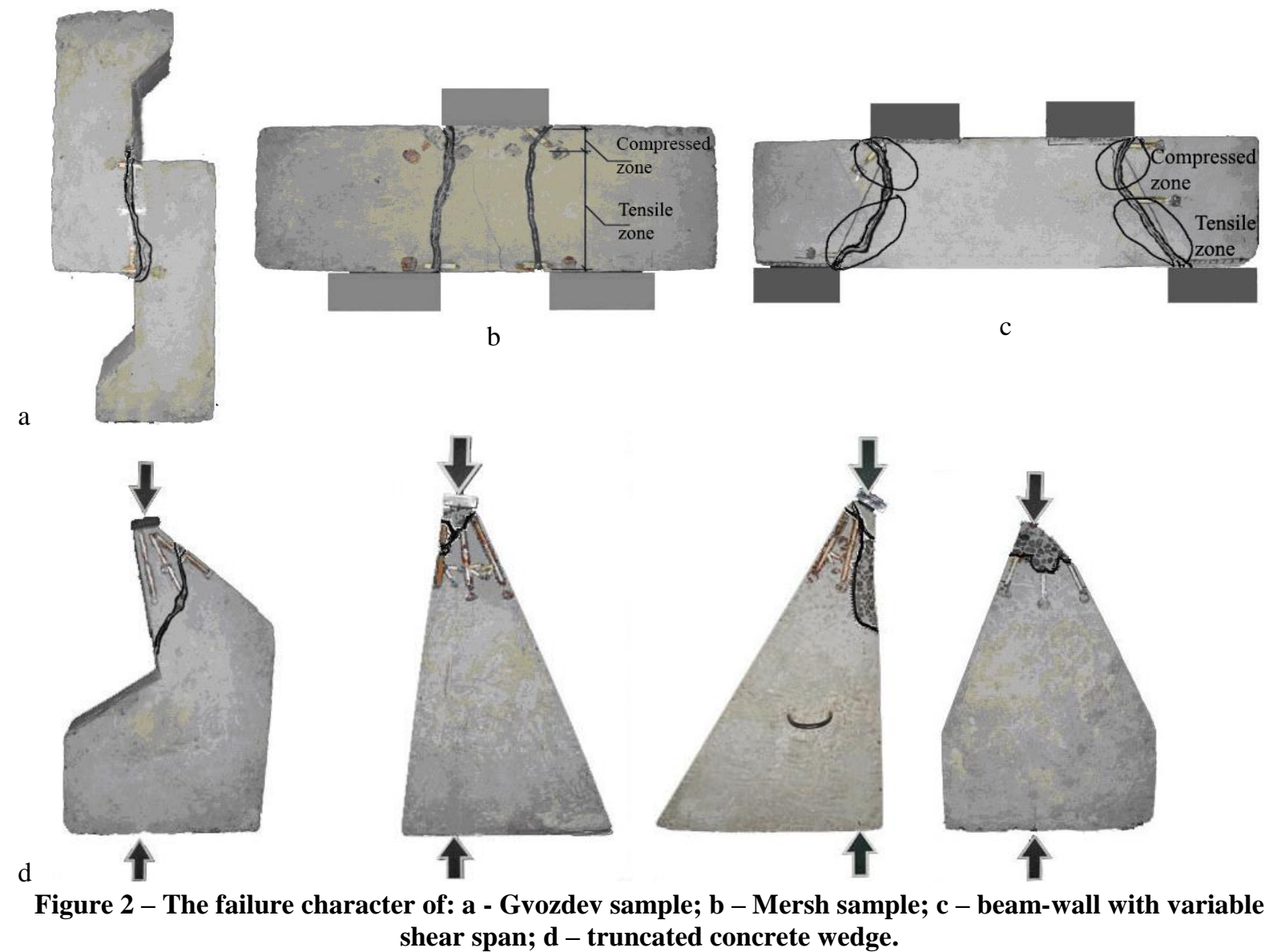

During testing truncated wedges of the first and second series collapsed near slant angle (case I), obtuse angle (case II) or both angles (case III) (fig. 2, d). The wedge strength doesn't depend from angle $\alpha$ in case I and rises with the increasing

of $\operatorname{tg} \beta$ value. The wedge strength reduces with the $\beta$ increasing and rises with the $\alpha$ increasing in case II realisation. The $\beta$ angle doesn't depend on strength in case III. Once angles meet $\square<\square+5 \square$ condition relationships "loading - strain" for compressed zone show the development of considerable plastic strain of concrete. For $\square \square \square+5 \square$ samples collapsed brittly. The received results conform with known data for heavy concrete by Mytrofanov V. [11] and confirm the possibility of application of the theory of plasticity for solving problems for the given type.

In addition wedges from higher strength concrete have been made and tested [3]. In testing samples considerable deformations have been observed in failure zone, their biggest values attained to magnitude of $\varepsilon_{c}=160 \times 10^{-5}$. The failure mode doesn't change relatively to samples of first and second series.

Convergence analysis of theoretical strength with experimental.
For each of the shear cases as the failure forms the mean arithmetic relation of theoretical $f_{s h}^{\text {calc }}$ to experimental $f_{s h}^{\text {test }}$ strength $\bar{X}=f_{\text {sh }}^{\text {calc }} / f_{\text {sh }}^{\text {test }}$, square mean deviation $\sigma_{n-1}$ and factor of a variation $v$ specified relation were determined.

Gvozdev samples. Data of 45 samples have been worked up $[6,8,15,16]$. Following values of statistic characteristics have been received: $\bar{X}=1,036, \sigma_{n-1}=0,181, v=17,43 \%$.

Mersh samples. The test results of 25 samples have been worked up [14, 17, 19, 21], for which the following statistic characteristics have been found: with reduced length of equal loading $l_{\text {red }}=2 l / 3$ $\left.\bar{X}=0,715, \quad \sigma_{n-1}=0,118, \quad v=16,5 \%\right)$ and $l_{\text {red }}=0,5 l($ $\left.\bar{X}=0,855, \sigma_{n-1}=0,142, v=16,7 \%\right)$. Thus $f_{c}$ varied in limits from $14 \mathrm{MPa}$ to $39 \mathrm{MPa}$, and $l / h$ varied from 0,4 to 1 .

Beam-walls with variable shear span. The results of researches of 13 samples have been worked up, for which the following statistic characteristics have been received: $\bar{X}=0,883, \quad \sigma_{n-1}=0,165$, $v=18,64 \%$.

Truncated concrete wedges. While comparing the experimental and theoretical strength of the truncated concrete wedges simulating the work of a

ISPC Generalization of scientific results, 


\begin{tabular}{|c|c|c|c|c|c|c|}
\hline Impact Factor: & $\begin{array}{l}\text { ISRA (India) } \\
\text { ISI (Dubai, UAF } \\
\text { GIF (Australia) } \\
\text { JIF }\end{array}$ & $\begin{array}{l}=1.344 \\
=0.829 \\
=0.564 \\
=1.500\end{array}$ & $\begin{array}{l}\text { SIS (USA) } \\
\text { PИНЦ (Russia) } \\
\text { ESJI (KZ) } \\
\text { SJIF (Morocco) }\end{array}$ & $\begin{array}{l}=0.912 \\
=0.234 \\
=1.042 \\
=\mathbf{2 . 0 3 1}\end{array}$ & $\begin{array}{l}\text { ICV (Poland) } \\
\text { PIF (India) } \\
\text { IBI (India) }\end{array}$ & $\begin{array}{l}=6.630 \\
=1.940 \\
=4.260\end{array}$ \\
\hline
\end{tabular}

compressed zone of concrete above DIC of reinforced concrete elements, for 112 samples (17 [8], $14-[16]$ and $81-[11])$ the following statistical characteristics have been received: $\bar{X}=0,9, \sigma_{n-1}=0,11$ , $v=12,22 \%$. Thus concrete strength of samples varied within the limits $f_{c}=7,2 \div 55,3 \mathrm{MPa}$.

\section{Conclusions}

For the solution of practical problems the various shear cases as the failure forms are of great importance. For all this the design of their strength is made by the empirical formulas having individual character, narrow area of applicability and insufficient accuracy limiting completeness of optimization and reliability of structures.

With the help of the sufficiently general method, based on concrete plasticity theory, the strength problem solution has been received for Gvozdev and Mersh samples at shear and truncated concrete wedges.
At complex non-uniform stress-strain states the externally brittle failure character cannot be the cause of impossibility to apply the plasticity theory to the concrete and reinforced concrete elements strength design. The precondition about ideal plasticity is applicable to concrete, if there are no tension zones in an element, causing brittle failure, or the stress level in them lags behind the stress level in the compressed zones. The results of the carried out experimental research have confirmed applicability of plasticity zones assumed in the theoretical solutions, and also the influence of strength factors, which were provided for by the design.

The theoretical strength is well coordinated with the experimental one.

Thus, the stated method of strength design for concrete and reinforced concrete elements under the action of shear forces combines important for practice advantages: accuracy, generality and comparative simplicity.

\section{References:}

1. Chakrabarti SC (1988) Shear Characteristics of Cast-in-Place Vertical Joints in Story-High Precast Wall Assembly / S. C. Chakrabarti, G. C. Nayak, D. K. Paul // ACI Struct. J - 1988. - Vol. 85 (1). - p. 30-45.

2. Christoffersen J (1997) Ultimate Capacity of Joints in Precast Large Panel Concrete Buildings. / J. Christoffersen // Department of Structural Engineering and Materials. Technical University of Denmark. - Series R No 25. - Lyngby. - 1997.

3. Dovzhenko OO (2011) Strength of the HighStrength Truncated Concrete Wedges. / O. O. Dovzhenko, O. O. Kurylenko, I. V. Akimenko // the Collection of the Proceedings (Resourceeconomy Materials, Constructions, Buildings and Structures). Rivne, 2011. - № 21. - p. 193 - 198.

4. Dovzhenko OO (2011) The Experimental Researches of Concrete Strength to Shear on Beam-Walls / O. O. Dovzhenko, V. V. Pogribnyi, T. Yu. Kachan, I. V. Akimenko // the Collection of the Proceedings (Resourceeconomy Materials, Constructions, Buildings and Structures). Rivne, 2011. - № 21. - p. 208 - 214.

5. Geniyev GA (1974) The Plasticity Theory of Concrete and Reinforced Concrete. /
G. A. Geniyev, V. N. Kyssyuk, G. A. Tyupin Moscow: Stroyizdat, 1974. - 326 p.

6. Gvozdev AA (1932) Study of Bond of New Concrete with Old / A. P. Vasilev, S. A. Dmitriev // M., L.: STI, 1932. - 54 p.

7. Jensen BC (1975) On the Ultimate Load of Vertical, Keyed Shear Joints in Large Panel Buildings. / B. C. Jensen // Technical report. Institute of Building Design. - Technical University of Denmark. - 1975.

8. Kachan TY (2012) Strength design of monolithic and glued reinforced concrete (concrete) elements on shear by variation method: thesis in getting of academic degree of doctor of science: speciality 05.23.01 - building constructions, buildings and structures / T. Yu. Kachan. - Poltava: PoltNTU, 2012. $232 \mathrm{p}$.

9. Mitrofanov VP (1999) Investigation of Destruction Zone Resistance of HSC of Beams Under Shear Forces Action/ V. P. Mitrofanov. // 5th Int. Symp. On Utilization of HS/HP Concrete, 20-24 June 1999, Sandefjord, Norway. Proceedings, Vol. 1. - p. 461 - 468.

10. Mitrofanov VP (1973) Limiting Load of the Truncated Concrete Wedge / V. P. Mitrofanov // the Building Mechanics and Design of Structures. - 1973. №1. - p. $20-24$. 


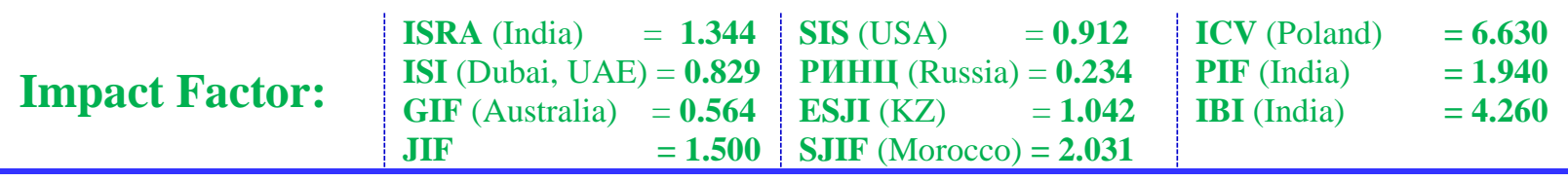

11. Mitrofanov VP (1982) Stress-Strain State, Strength and Cracking of Reinforced Concrete Elements under a Cross Bend: autoabstract to thesis in getting of academic degree of doctor of science: speciality 05.23.01 - building constructions, buildings and structures / V. P. Mitrofanov. - Moscow: VZISI, 1982. $42 \mathrm{p}$.

12. Mitrofanov VP (1990) The Variation Method in the Theory of Ideal Plasticity of Concrete / V.P. Mitrofanov // the Building Mechanics and Design of Structures. - 1990. - №6. - p. 23-28.

13. Nielsen MP (2011) Limit Analysis and Concrete Plasticity / M. P. Nielsen, L. C. Hoang // CRC Press, Taylor \& Francis Group, third edition - 2011. - $669 \mathrm{p}$.

14. Petrov AN (1967) About Interpretation of Shear in Concrete / A. N. Petrov // Building Structures. - K.: Designer, 1967. - Vol. VI. - p. $181-188$.

15. Petrov AN (1962) Shear Concrete Strength Presence of Normal Compressing Stress / A. N. Petrov // the Collection of the Proceedings. - Dnepropetrovsk. - 1962. - Vol. 19. - p. $19-32$.

16. Pogrebnoy VV (2001) Strength of Concrete and Reinforced Concrete Elements at Shear: thesis in getting of academic degree of doctor of science: speciality 05.23.01 - building constructions, buildings and structures / V. V. Pogrebnoy. - Poltava: PSTU, 2001. - 236 p.

17. Sorensen JH (2016) Construction-Friendly Ductile Shear Joints for Precast Concrete Panels. / J. H. Sorensen, L. C. Hoang, G. Fisher, J. F. Olesen.

18. Stolyarov YV (1941) Introduction in the Theory of Reinforced Concrete. / Ya. V. Stolyarov // M., L.: State Publishing House of Structure Literature, 1941. - 448 p.

19. Stolyarov YV (1934) The Theory of Reinforced Concrete on the Experimental Basis. / Ya. V. Stolyarov // Charkov: ONTI - GNTIY, 1934. - $224 \mathrm{p}$.

20. (2002) Strength of Short Concrete Beams at Shear / [O. O. Dovzhenko, V. V. Pogribnyi and others] // the Collection of the Proceedings (Resourceeconomy Materials, Constructions, Buildings and Structures). - Rivne, 2002. - № 8. - p. $108-115$.

21. Verigin KP (1960) Strength of Concrete at Joint Influence of Axial and Cross Forces / K. P. Verigin // Concrete and Reinforced Concrete. - 1960. - № 10. - p. 479 - 480. 